\title{
Remarkable Evolutionary Plasticity of Centromeric Chromatin
}

\author{
Steven Henikoff, ${ }^{1,2}$ Jitendra Thakur, ${ }^{1,2}$ Sivakanthan Kasinathan, ${ }^{2,3}$ \\ AND PAUl B. TALBERT ${ }^{1,2}$ \\ ${ }^{1}$ Howard Hughes Medical Institute, Fred Hutchinson Cancer Research Center, Seattle, \\ Washington 98109 \\ ${ }^{2}$ Basic Sciences Division, Fred Hutchinson Cancer Research Center, Seattle, Washington 98109 \\ ${ }^{3}$ Medical Scientist Training Program, University of Washington School of Medicine, Seattle, \\ Washington 98195 \\ Correspondence: steveh@fhcrc.org
}

\begin{abstract}
Centromeres were familiar to cell biologists in the late 19th century, but for most eukaryotes the basis for centromere specification has remained enigmatic. Much attention has been focused on the cenH3 (CENP-A) histone variant, which forms the foundation of the centromere. To investigate the DNA sequence requirements for centromere specification, we applied a variety of epigenomic approaches, which have revealed surprising diversity in centromeric chromatin properties. Whereas each point centromere of budding yeast is occupied by a single precisely positioned tetrameric nucleosome with one cenH3 molecule, the "regional" centromeres of fission yeast contain unphased presumably octameric nucleosomes with two cenH3s. In Caenorhabditis elegans, kinetochores assemble all along the chromosome at sites of cenH3 nucleosomes that resemble budding yeast point centromeres, whereas holocentric insects lack cenH3 entirely. The "satellite" centromeres of most animals and plants consist of cenH3-containing particles that are precisely positioned over homogeneous tandem repeats, but in humans, different $\alpha$-satellite subfamilies are occupied by CENP-A nucleosomes with very different conformations. We suggest that this extraordinary evolutionary diversity of centromeric chromatin architectures can be understood in terms of the simplicity of the task of equal chromosome segregation that is continually subverted by selfish DNA sequences.
\end{abstract}

Centromeres have been familiar to cell biologists even before the rediscovery of Mendel's laws. In 1882, Walther Flemming used cytological stains to observe mitotic figures, which he called "chromatin" (Flemming 1882). In his drawings of lily chromosomes at metaphase and anaphase, Flemming darkly shaded the chromatin corresponding to each site of spindle fiber attachment, which later was referred to as the centromere or kinetochore. By current usage, the centromere refers to the genetic locus, whereas the kinetochore is the large complex of proteins specifically bound to centromeric DNA (Talbert et al. 2008). A further distinction can be made between the inner kinetochore proteins that remain associated with the DNA throughout the cell cycle, referred to as the centromeric chromatinassociated network (CCAN), and protein complexes of the outer kinetochore that assemble at mitosis.

The classical work of Morgan and his students genetically defined the centromere as a locus (Sturtevant 1913). But the molecular study of the centromere began in earnest in 1980, when Clarke and Carbon genetically mapped the centromere of Saccharomyces cerevisiae (budding yeast) Chromosome III to a 1.6-kb DNA segment (Clarke and Carbon 1980). When they inserted this DNA segment into a circular plasmid vector with a replication origin, they observed faithful segregation through mitosis and meiosis.

The molecular description of proteins of the CCAN began with the discovery by Earnshaw and Rothfield of what they termed Centromere Proteins A, B, and C (CENP$\mathrm{A}$, CENP-B, and CENP-C) using human autoimmune antibodies (Earnshaw and Rothfield 1985). Meanwhile, Palmer and Margolis (1985) showed that bovine CENPA is a histone H3 variant (Palmer et al. 1987), one that remains with the DNA in mature sperm (Palmer et al. 1990). This was the first suggestion that centromeres might be "epigenetic" - that is, defined by the presence of the centromere-specific histone variant, which we refer to generically as "cenH3" to conform to the well-established histone nomenclature (Bradbury 1977; Talbert et al. 2012). Understanding the basis for this dual definition of centromeres as genetic and/or epigenetic has been a driving force for work in the laboratory for almost two decades.

Centromeres are generally conserved in position along the chromosome over evolutionary time; however, surprisingly this is not the case for centromeric DNA sequence. The realization that centromeric DNA has been rapidly evolving came from studies in the 1960s of satellite DNA, tandem repeats that could be separated from main-band DNA in buoyant density gradients and that differed between even closely related species (Yunis and Yasmineh 1971). The discovery that the sequence of the S. cerevisiae cenH3 (Cse4) is as divergent from $\mathrm{H} 3$ as it is from human CENP-A (Meluh et al. 1998) was another clue suggesting that centromeres are not under the same evolutionary constraints as are genes and their DNA-bind-

(C) 2017 Henikoff et al. This article is distributed under the terms of the Creative Commons Attribution License, which permits unrestricted reuse and redistribution provided that the original author and source are credited. 
ing proteins. These considerations led us to identify and characterize cenH3s from diverse model organisms, including Caenorhabditis elegans (Buchwitz et al. 1999), Drosophila melanogaster (Henikoff et al. 2000), Arabidopsis thaliana (Talbert et al. 2002), rice (Nagaki et al. 2004), and maize (Jin et al. 2004). Indeed, we found that evolutionary divergence is a general feature of cenH3s, despite the fact that $\mathrm{H} 3$ and its general replacement variant, H3.3, are among the most highly conserved proteins known. We referred to the remarkable divergence of both centromeric satellite DNA and its dedicated histone as the centromere paradox: rapid evolution with a conserved function that is essential through every cell division (Henikoff et al. 2001).

Harmit Malik in the laboratory made the key observation that Drosophila cenH3 (Cid) is evolving adaptively using standard population genetic measures, suggesting an arms race (Malik and Henikoff 2001). Reasoning that the arms race would be between centromeric satellites and cenH3, we posited that centromeres compete for inclusion into the egg at female meiosis I (Henikoff et al. 2001). Our "centromere drive" hypothesis combined the concept of female meiotic drive described by Rhoades for the selfish segregation behavior of distal heterochromatic knobs in maize (Rhoades 1952) with that of centromere "strength" for the inferred female meiotic orientation of heterochromatinrich centromeres by Novitski (1955). Centromere drive as an explanation for the centromere paradox has since become the standard explanation for centromere divergence based on evidence from humans (Daniel 2002), monkey flowers (Fishman and Willis 2005), and mice (Chmátal et al. 2014) and an attractive general mechanism for postzygotic reproductive isolation as species diverge (Henikoff and Malik 2002; Burt and Trivers 2006).

The realizations that satellite centromeres are selfish and that cenH3s and other CCAN proteins may act to suppress drive (Talbert et al. 2004) raise the question as to how these CCAN proteins interact with their DNA substrates. We started by studying $S$. cerevisiae centromeres, with simple point centromeres that provide a basis for comparison to the more complex regional centromeres of Schizosaccharomyces pombe, the holocentromeres of C. elegans and holocentric insects, and the satellite centromeres of humans. In each case we have applied high-resolution mapping technologies to address the basic problem of centromere specificity. We find that the evolutionary divergence of centromeric chromatin is reflected in the plasticity of CCAN complex composition between different organisms and sometimes of different centromeres of the same individual.

\section{BUDDING YEAST CENTROMERES ARE OCCUPIED BY HEMISOMES}

Based on a comparison of centromeres from different budding yeast chromosomes, Clarke and Carbon (1985) identified consensus motifs that they termed centromeredetermining element (CDE) I, II, and III. Subsequent work identified the $\sim 120$-bp segment spanning CDEIII-III as the sequence-specific core of each of the 16
S. cerevisiae centromeres. The 8-bp CDEI consensus is the binding site for the Cbfl sequence-specific transcription factor, and the 26-bp CDEIII consensus is the binding site for the centromere-specific multisubunit CBF3 complex. These elements flank the $82 \pm 4$-bp CDEII, which lacks a specific consensus, but consists of $\geq 90 \%$ AT-rich DNA. Micrococcal nuclease (MNase) mapped a single Cse4 nucleosome to the functional centromere (Furuyama and Biggins 2007). This observation is difficult to reconcile with the availability of only $\sim 80$ bp of DNA for wrapping, suggesting the presence of a particle with fewer than the eight subunits in an $\mathrm{H} 3$ nucleosome, which wraps 147 bp of DNA.

To address this conundrum, Takehito Furuyama determined the chirality of the DNA superhelical writhe around the Cse4-containing core, using superhelical density mapping of circular chromosomes. This analysis revealed that the budding yeast centromere induces positive DNA supercoils, indicative of a right-handed writhe around the particle, opposite to that of left-handed H3 nucleosomes (Furuyama and Henikoff 2009). Our supercoiling measurements were later confirmed and extended in a study suggesting that the right-handed configuration is enforced by the formation of a DNA loop held together by the CBF3 complex, excluding CDEI (Díaz-Ingelmo et al. 2015). A possible rationale for the right-handed superhelical wrap is that DNA overwinds when stretched (Gore et al. 2006), so that pulling on the centromere at anaphase would be expected to cause the (right-handed) DNA to tighten around the particle.

Using a new high-resolution native chromatin immunoprecipitation (ChIP) method with V-plot analysis (Henikoff et al. 2011), Krassovsky et al. (2012) succeeded in mapping the Cse4-containing particle directly over CDEII. Meanwhile, some cytological studies detected more fluorescent Cse4-GFP particles over centromeres than could plausibly fit within CDEII (Coffman et al. 2011; Lawrimore et al. 2011), challenging the "point" interpretation of yeast centromeres (Furuyama and Biggins 2007). However, our quantitative ChIP-seq data could exclude the possibility that additional molecules are incorporated outside of the genetically defined centromere (Henikoff and Henikoff 2012), rather suggesting that unincorporated Cse4 molecules are closely associated with functional centromeres. Thus, only two plausible models for the budding yeast centromere remained: a $(\mathrm{Cse} 4 / \mathrm{H} 4)_{2}$ "tetrasome" or a (Cse4/H4/H2A/H2B) "hemisome," either of which could wrap the $\sim 80$-bp CDEII DNA with right-handed chirality.

To determine whether hemisomes can be assembled on short segments of DNA, Takehito Furuyama adopted a classical salt-assembly method (Tatchell and Van Holde 1979), demonstrating that $\mathrm{Cse} 4$ but not $\mathrm{H} 3$ hemisomes that are stable in $4 \mathrm{M}$ urea can be readily produced on CDEII DNA (Furuyama et al. 2013). Our finding suggested that the extreme AT richness of CDEII is an adaptation for exclusion of conventional nucleosomes from the functional centromere, as poly $(\mathrm{dA}: \mathrm{dT})$ tracts in the yeast genome are known to exclude nucleosomes (Struhl and Segal 2013).

To definitively determine the composition and conformation of the budding yeast centromeric nucleosome in vivo, we applied the Widom chemical cleavage mapping 
method, in which histone $\mathrm{H} 4$ is derivatized such that it cleaves DNA next to the dyad (Brogaard et al. 2012). By mapping the sites of cleavage, we could determine the precise location of $\mathrm{H} 4$ with base-pair resolution and also determine whether there is one $\mathrm{H} 4$ or two H4s. Results were unequivocal: Mapping of $\mathrm{H} 4$ cleavages at all 16 yeast centromeres showed only a single H4 with cleavage sites within CDEII consistent with a hemisome and only with a hemisome among all proposed structures (Henikoff et al. 2014) (Fig. 1, middle panel). More recently, we have used our novel CUT\&RUN chromatin profiling method (Skene and Henikoff 2017) to show the presence of histone H2A in the CDEII particle (Fig. 2), definitively excluding the $(\mathrm{Cse} 4 / \mathrm{H} 4)_{2}$ tetrasome model (Mizuguchi et al. 2007; Wisniewski et al. 2014).

\section{FISSION YEAST CENTROMERES LACK POSITIONING AND ARE POPULATED BY OCTAMERIC NUCLEOSOMES}

Examination of the fungal phylogeny argues that point centromeres, which are exclusive to the Saccharomycetes, have evolved from "regional" centromeres that lack obvious sequence specificity (Malik and Henikoff 2009). For example, centromeres of the parasitic budding yeast $\mathrm{Can}$ dida albicans show no sequence similarity to those of its close relative Candida dubliniensis (Padmanabhan et al. 2008), and deletion or replacement results in efficient formation of cenH3-enriched neocentromeres nearby (Baum et al. 2006; Ketel et al. 2009; Thakur and Sanyal 2013). Centromeres of the fission yeast $S$. pombe consist
A

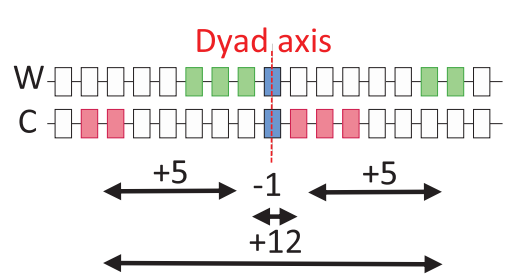

S. cerevisiae $\quad \begin{array}{lll}-1 & 5 & 12\end{array}$

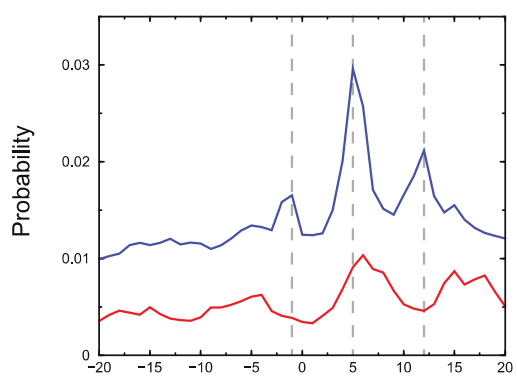

S. pombe

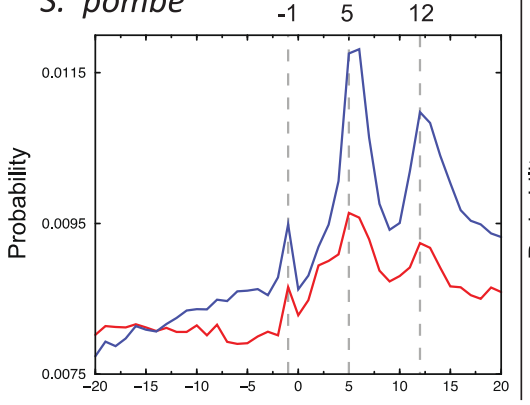

$(\mathrm{W}-\mathrm{C})$ Distance (bp)
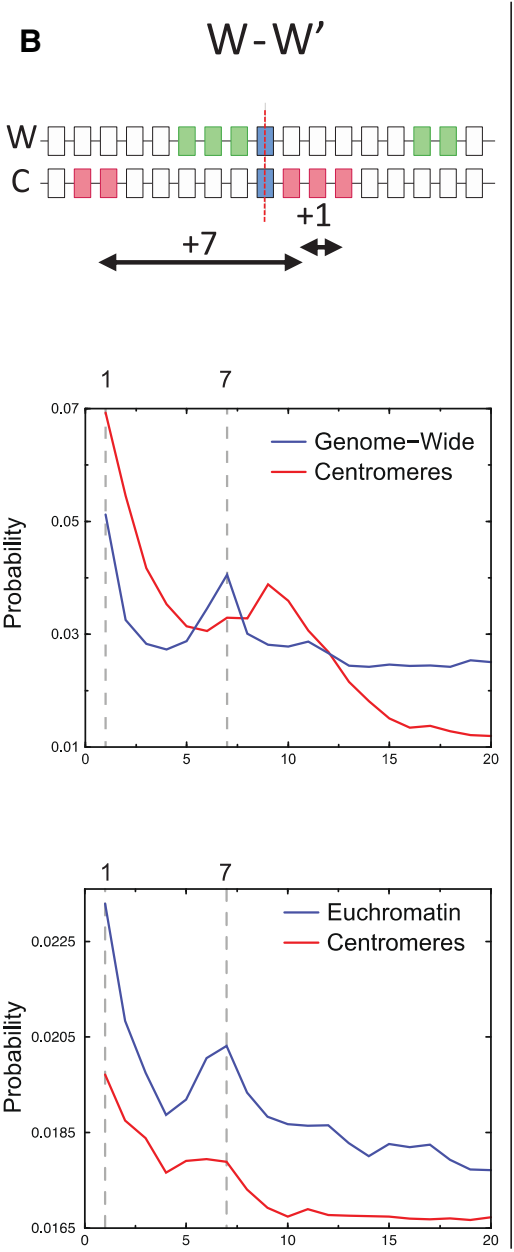

( W - W' ) Distance (bp)
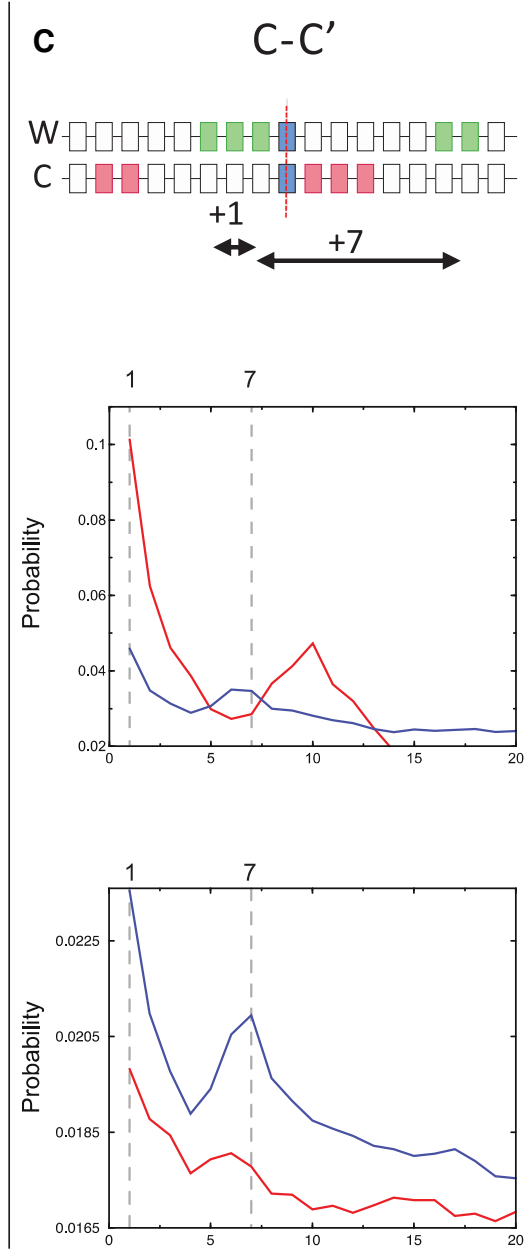

( C - C') Distance (bp)

Figure 1. Budding yeast centromeric nucleosomes have one histone H4, but those in fission yeast have two. In vivo chemical cleavage mapping shows one CENP-A H4 molecule for Saccharomyces cerevisiae but two for Schizosaccharomyces pombe. $(A-C)($ Top) A structure-based model of where H4S47C-anchored cleavages are predicted to occur on the Watson (W, $\left.5^{\prime} \rightarrow 3^{\prime}\right)$ and Crick $\left(\mathrm{C}, 3^{\prime} \rightarrow 5^{\prime}\right)$ strands around the dyad axis of an $\mathrm{H} 3$ nucleosome (Henikoff et al. 2014). Each box represents a single nucleotide position, where the filled boxes are predicted cleavage sites on the $\mathrm{W}$ strand (green) and the $\mathrm{C}$ strand (pink). The predicted distances between cleavage sites are indicated below. (Middle) Distribution of distances between cleavage fragment ends genome-wide (blue lines) and for budding yeast centromeres (red lines) (Henikoff et al. 2014). (Bottom) Comparable distributions for the central core of fission yeast centromeres (red lines) and euchromatin (blue lines) (Thakur et al. 2015). Distributions were normalized by the total number of combinations within the 40-bp distance range. $(A) \mathrm{W}-\mathrm{C}$ distances. $(B) \mathrm{W}-\mathrm{W}^{\prime}$ distances. $(C) \mathrm{C}-\mathrm{C}^{\prime}$ distances. (Adapted from Thakur et al. 2015, with permission from the Genetics Society of America.) 
A

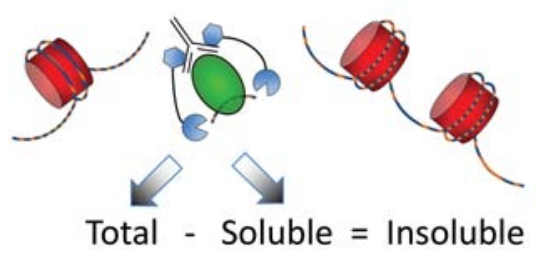

B
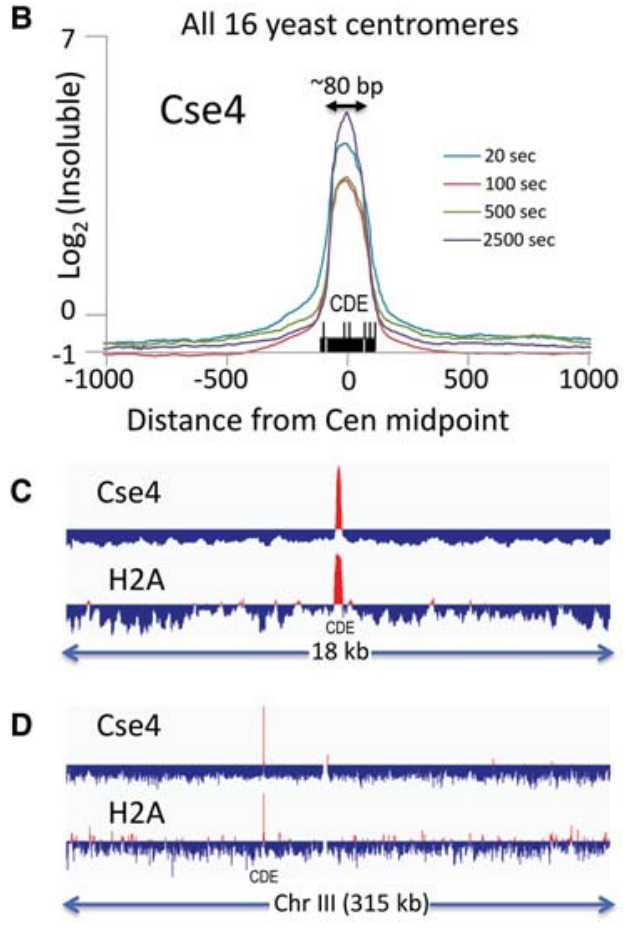

Figure 2. Budding yeast centromeres are occupied by insoluble kinetochore-bound 80-bp particles containing Cse 4 and $\mathrm{H} 2 \mathrm{~A}$. (A) CUT\&RUN releases chromatin particles by $\mathrm{Ca}^{2+}$-dependent cleavage on either side when ProteinA/MNase (blue) is tethered to an antibody (Skene and Henikoff 2017). Insoluble chromatin is measured by splitting the sample after MNase digestion and extracting the soluble and total DNA, where the difference represents insoluble chromatin. (B) Cse4 (cenH3) CUT\&RUN log-ratio profiles of insoluble chromatin over a $>2$ order of magnitude time course shows the presence of a stable $\sim 80$-bp Cse4-containing particle over CDEII. $(C)$ Similar CUT\&RUN profiles are seen for Cse4 and H2A over Centromere III (2500sec time point), ruling out the $(\mathrm{Cse} 4 / \mathrm{H} 4)_{2}$ tetrasome model (Mizuguchi et al. 2007). (D) The Cse4/H2A-containing centromeric nucleosome is the most insoluble nucleosome on the entire chromosome.

of a series of heterochromatic outer repeats flanking a cenH3-rich core that lacks obvious sequence-specific features. Thus it would appear that budding yeast point centromeres have emerged from a fungal ancestor that lacks sequence-specific centromeres, perhaps the result of colonization by the $2-\mu \mathrm{m}$ parasitic element that segregates autonomously within the Saccharomycetes (Malik and Henikoff 2009).

Consistent with an independent origin of point centromeres from regional centromeres, we have found that the cenH3 nucleosomes at the centromeric core of $S$. pombe regional centromeres are completely different from those of S. cerevisiae. Fission yeast cenH3 nucleosomes show no detectable positioning within the central core, and $\mathrm{H} 4$ chemical cleavage mapping reveals that there are two H4s per particle (Fig. 1, bottom panel), indicative of octameric nucleosomes (Thakur et al. 2015). Thus, the extreme diversity of centromere architecture is reflected in the diversity of centromeric chromatin within the fungal lineage, where point centromeres are bound by well-phased hemisomes and regional centromeres are bound by unphased octasomes.

\section{ELEGANS HOLOCENTROMERES ARE POLYCENTRIC}

The most fundamental distinction between centromeres is the distinction between familiar monocentromeres and holocentromeres, in which microtubule attachments occur throughout the length of the chromosome. Our cloning and cytological characterization of cenH3 from the nematode worm C. elegans revealed that it occupies the leading edge of each sister chromosome as it segregates to the pole at mitosis, and absence of cenH3 within the bulk of chromatin implied that holocentromeres are discontinuous (Buchwitz et al. 1999). Standard ChIP-seq uncovered a large domain structure of low-density cenH3 (Gassmann et al. 2012), and Florian Steiner's high-resolution native ChIP revealed the presence of approximately 100 well-positioned cenH3 loci dispersed throughout each chromosome (Steiner and Henikoff 2014). Remarkably, these centromeric loci resembled yeast point centromeres with particle sizes of $\sim 80$ bp flanked by well-phased H3 nucleosomes (Fig. 3). Motif analysis showed that holocentromeres correspond to previously described GA-rich transcription factor hotspots (Gerstein et al. 2010), leading us to speculate that low-affinity binding of transcription factors at these sites during interphase prevents encroachment by flanking nucleosomes, thus maintaining holocentromere sites accessible at mitosis throughout development (Steiner and Henikoff 2014).

The mapping of dispersed point centromeres at transcription factor hotspots throughout $C$. elegans chromosomes addressed a long-standing question in chromosome biology by showing that holocentromeres are polycentric as opposed to being diffuse (Schrader 1935). More recently, native ChIP-seq of centromeres of the parasitic nematode Ascaris suum suggested that these centromeres are also polycentric, but they do not appear to be point centromeres in that cenH3-rich regions consist of high-density arrays of $1-15 \mathrm{~kb}$, with particle sizes of $\sim 140 \mathrm{bp}$, consistent with conventional octasomes (Kang et al. 2016).

\section{INSECT HOLOCENTROMERES LACK cenH3}

Holocentricity has evolved in multiple lineages of animals and plants (Melters et al. 2012). For example, holocentromeres have evolved independently in insects at least four times (Drinnenberg et al. 2014). When Ines Drinnenberg was a postdoctoral fellow jointly with the Malik laboratory, she discovered that cenH3 and other 
A

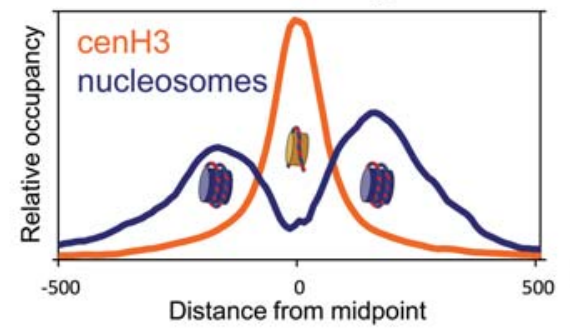

B

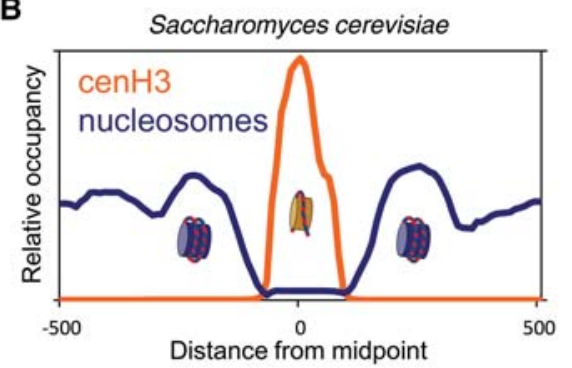

C

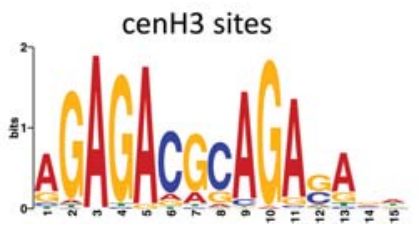

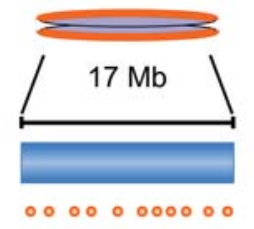

entire chromosome

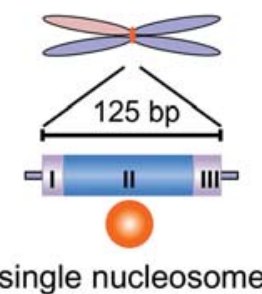

TF hotspots

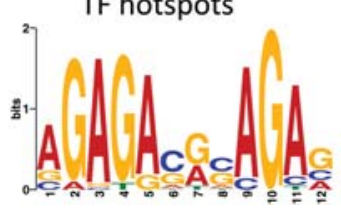

Figure 3. Caenorhabditis elegans holocentromeres are polycentric with dispersed point centromeres at transcription factor hotspots. $(A)$ cenH3 native MNase ChIP-seq peaks $(n=707)$ were called and aligned at their midpoints. The orange curve represents the average cenH3/ input profile, and the blue curve represents the input profile for paired-end reads in the 141-500-bp range. $(B)$ For comparison, the equivalent profile is shown for alignment of MNase ChIP-seq and input data from Saccharomyces cerevisiae. (C) Sequence logo representations of the consensus motif at cenH3 peaks (left) and transcription factor hotspots (right) called using MEME (Bailey and Elkan 1994). (Adapted from Steiner and Henikoff 2014.) proteins of the CCAN are absent from holocentric Lepidopteran lineages. Remarkably, loss of these CCAN proteins coincided with all four known transitions from monocentricity to holocentricity in insects (Fig. 4). In contrast, proteins of the outer kinetochore are nearly universally conserved, including in the kinetoplastid Trypanosoma, which also lacks canonical CCAN proteins (Akiyoshi and Gull 2014; Senaratne and Drinnenberg 2017). Identifying the chromatin counterparts of the CCAN in these lineages and determining whether insect holocentromeres are polycentric or diffuse are issues that remain to be addressed (Drinnenberg et al. 2016).

\section{PRECISE POSITIONING OF cenH3 NUCLEOSOMES AT SATELLITE CENTROMERES}

The identification of CENP-A nucleosomes as marking functional mammalian centromeres (Palmer and Margolis 1985) was an important advance in centromere biology. However, it was not until 1997 that the equivalent of the Clarke and Carbon construction of a functional centromere was accomplished for a satellite centromere (Harrington et al. 1997). Most human artificial centromeres require hundreds of kilobases of an $\sim 170$-bp $\alpha$-satellite repeat array organized as higher-order repeats (HORs), including $\sim 17$-bp consensus binding sites for CENP-B protein (Hayden et al. 2013). Several studies have used ChIP-seq to show that CENP-A nucleosomes occupy $\alpha$ - satellite sequences, although the exact composition and conformation of the particles continue to be debated (Bui et al. 2012; Hasson et al. 2013; Lacoste et al. 2014; Athwal et al. 2015; Henikoff et al. 2015; Thakur and Henikoff 2016; Nechemia-Arbely et al. 2017). We have found that much of the disagreement stems from the difficulty of mapping ChIP-seq reads to tandemly repeated DNA sequences, which have proven to be intractable using standard tools for sequence assembly. To circumvent this problem, we clustered CENP-A ChIP-seq reads de novo, identifying two families of homogeneous dimeric repeats with CENP-B boxes that dominate human centromeres (Henikoff et al. 2015). This extended earlier work of Alexandrov et al. (2001), who originally identified these two "suprachromosomal" $\alpha$-satellite families, SF1 and SF2, as homogeneous dimeric arrays present on 20 of the 24 different human centromeres. Indeed, we identified a preponderance of precisely positioned 100-bp MNase protected particles for these two dominant families, but we also identified larger particles for other HORs, such as the DXZ1 SF3 subfamily (Fig. 5), that are less homogeneous in CENP-A ChIP-seq data (Henikoff et al. 2015). Our findings suggested that particle conformation detected by native MNase ChIP-seq can differ greatly between different human $\alpha$-satellite families, with precise positioning a characteristic of the most homogeneous repeats. Precise rotational positioning of cenH3 nucleosomes is a feature of homogeneous satellite centromeres in rice, as determined in a collaborative ChIP-seq study from the Jiming Jiang laboratory (Zhang et al. 2013). 


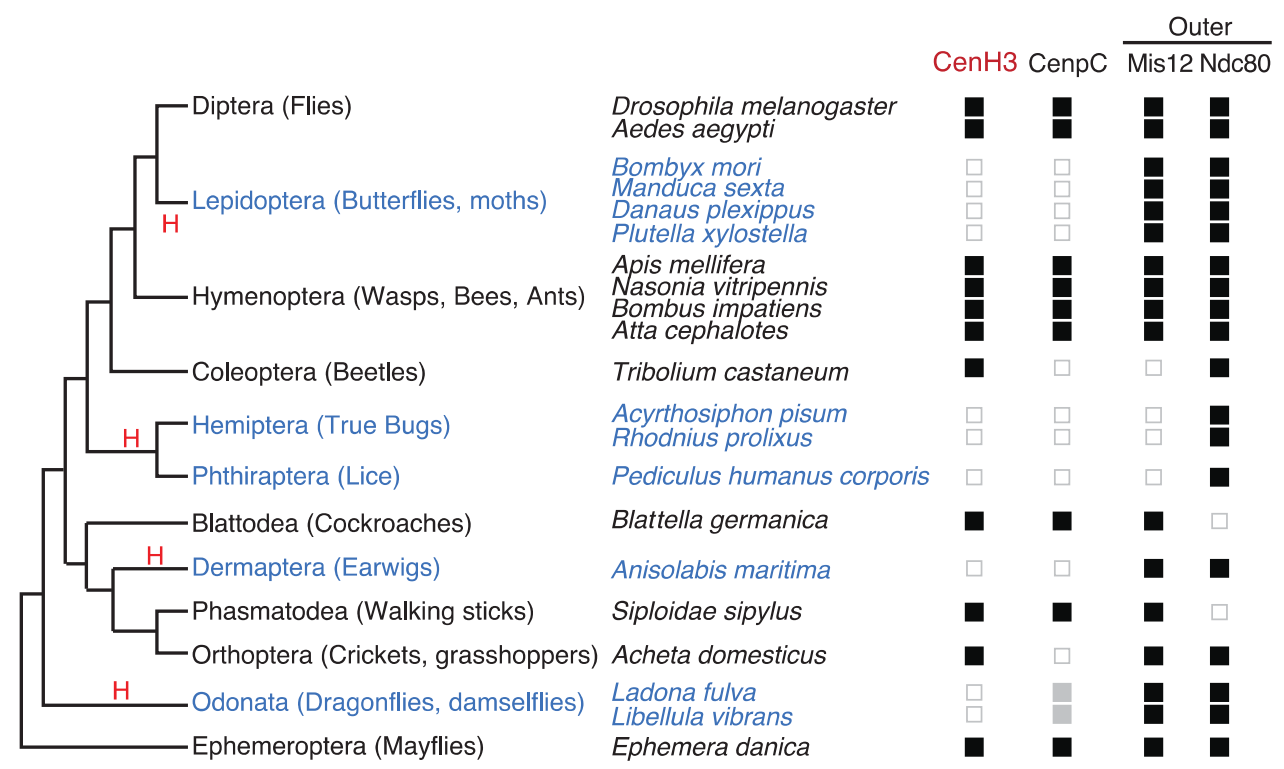

Figure 4. Insect holocentromeres lack cenH3. Four separate transitions from monocentric to holocentric kinetochores have occurred within insect evolution (red $\mathrm{H}$ ). In each case, the transition involves loss of the inner kinetochore proteins cenH3 and CENP-C, except in Odonata, where CENP-C is retained but no longer has the CENPC motif that recognizes cenH3. Outer kinetochore components, notably $\mathrm{Ndc} 80$, which attaches directly to microtubules, are generally preserved. (Adapted from Drinnenberg et al. 2014.)

\section{A COHERENT INNER KINETOCHORE COMPLEX OCCUPIES YOUNG HUMAN CENTROMERIC REPEATS}

Whereas we and others had observed 100-bp $\alpha$-satellite particles using native MNase-based ChIP-seq (Hasson et al. 2013; Henikoff et al. 2015), we also found that formaldehyde cross-linking resulted in protection of particles that were larger than nucleosome size (Thakur and Henikoff 2016). This observation suggested that MNase cleavage under the conditions we used for native ChIPseq was disrupting particle integrity, but that cross-linking held together a particle consisting of additional components. In our ChIP-seq study of fission yeast centromeres, we had identified CENP-T as an integral component of CENP-A and CENP-C enriched chromatin (Thakur et al. 2015). However, we initially failed to identify human CENP-T by native MNase-based ChIP-seq, consistent with the prevailing view that in mammals CENP-T makes connections with $\mathrm{H} 3$ but not CENP-A nucleosomes (McKinley and Cheeseman 2016). As connections to the outer kinetochore are made independently by both CENP-C and CENP-T, the concept of separate anchors for the kinetochore on the DNA was a central issue in understanding centromere biology. The possibility of independent connections between centromeric DNA and the outer kinetochore seemed plausible, insofar as CENP-T and its three partner proteins in the CENP-TWSX complex should be sufficient to directly anchor the outer kinetochore: All four are histone-fold proteins that can be assembled in vitro into nucleosome-like particles that stably wrap DNA in a right-handed orientation. But we wondered: Could it be that the CENP-TWSX particle accounts for the difference in protection by CENP-A/CENP-C par- ticles using native versus formaldehyde cross-linking MNase-ChIP?

To directly address this possibility, we reasoned that the conditions that are used for MNase ChIP-seq might leave behind more condensed particles. Differential salt solubility is a feature of conventional nucleosomes, which can be fractionated into classical "active" (low- $\mathrm{NaCl}$ ), histone $\mathrm{H} 1-$ rich (high- $\mathrm{NaCl}$ ), and "nuclear matrix" (insoluble) components (Sanders 1978; Henikoff et al. 2009). Indeed, using cross-linking and light sonication after MNase digestion, we found that CENP-T containing $\alpha$-satellite particles could be recovered in robust amounts, and CENP-T particles precisely co-mapped with CENPA and CENP-C (Thakur and Henikoff 2016). It is possible that estimated particle size differences reported in studies using native MNase ChIP-seq (Hasson et al. 2013; Lacoste et al. 2014; Henikoff et al. 2015; Nechemia-Arbely et al. 2017) can be explained by the lability of CENP-TWSX-containing particles when subjected to MNase treatment.

To confirm that a coherent CCAN particle containing CENP-A, CENP-C, and CENP-T occupies functional human centromeres, we performed tandem ChIP-seq on FLAG-CENP-A particles subjected to cross-linking and heavy digestion with MNase to produce single coherent particles. After first immunoprecipitating with an antiFLAG antibody and eluting with FLAG peptide, we immunoprecipitated with CENP-A, CENP-B, CENP-C, and CENP-T antibodies, obtaining strong enrichment for each component (Fig. 6). Enrichment was seen for consensus sequences representing SF1, SF2, and SF3 subfamilies and for the $\mathrm{Y}$ centromere, which indicates that at all human centromeres a single CCAN complex contains four of these centromere-specific DNA-binding components. 
A
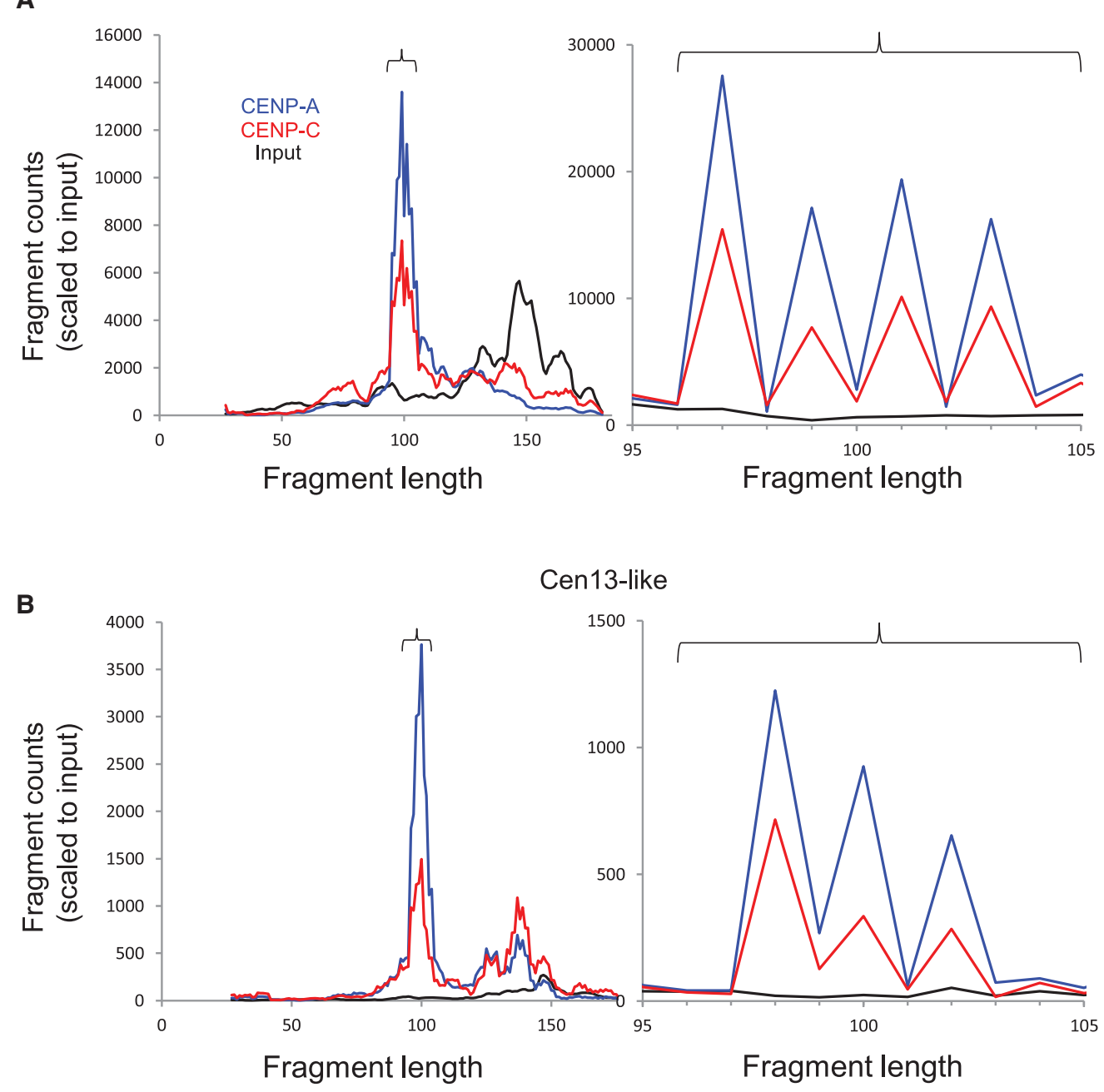

C

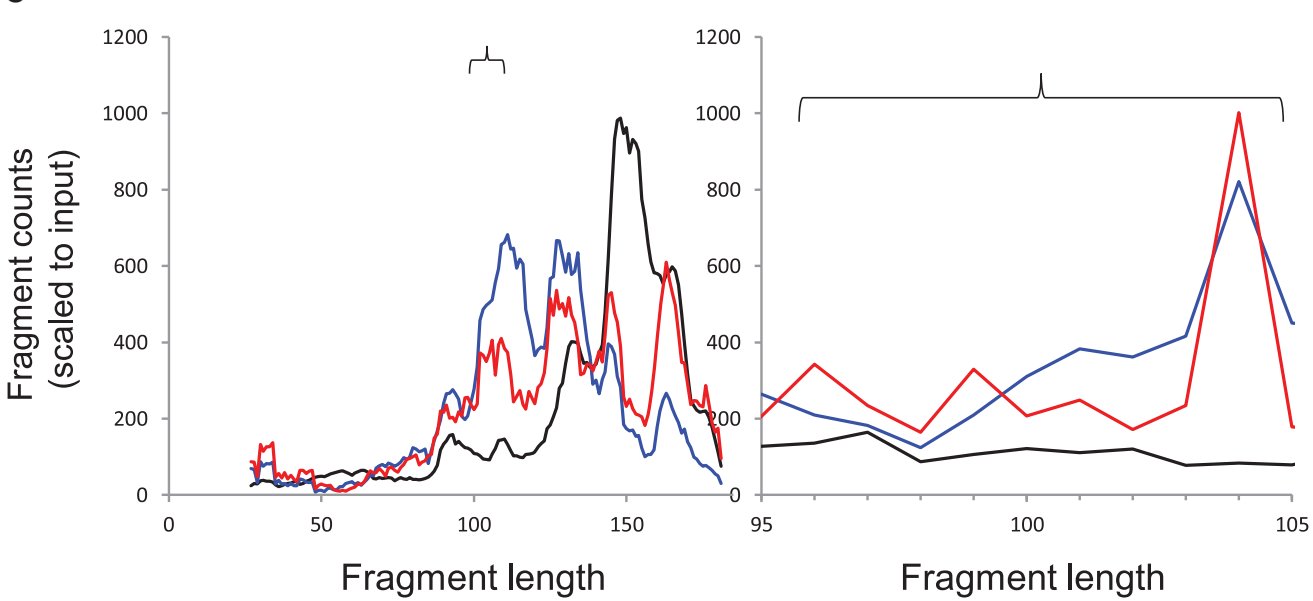

Figure 5. Precise positioning of cenH3 nucleosomes at human $\alpha$-satellite centromeres. Young $\alpha$-satellite dimers precisely position $\sim 100$-bp CENP-A nucleosome particles. $(A-C)$ Size distributions of fragments mapping to an SF1 consensus dimer $(A)$ and an SF2 consensus dimer $(B)$ and to the most proximal 6-kb region of DXZ1 $(C)$, which belongs to SF3. Graphs on the right are expansions of graphs on the left (indicated by brackets). The $y$-axis scale is for input normalized counts, and the areas under the other curves were equalized to that for input. (Reprinted from Henikoff et al. 2015.) 


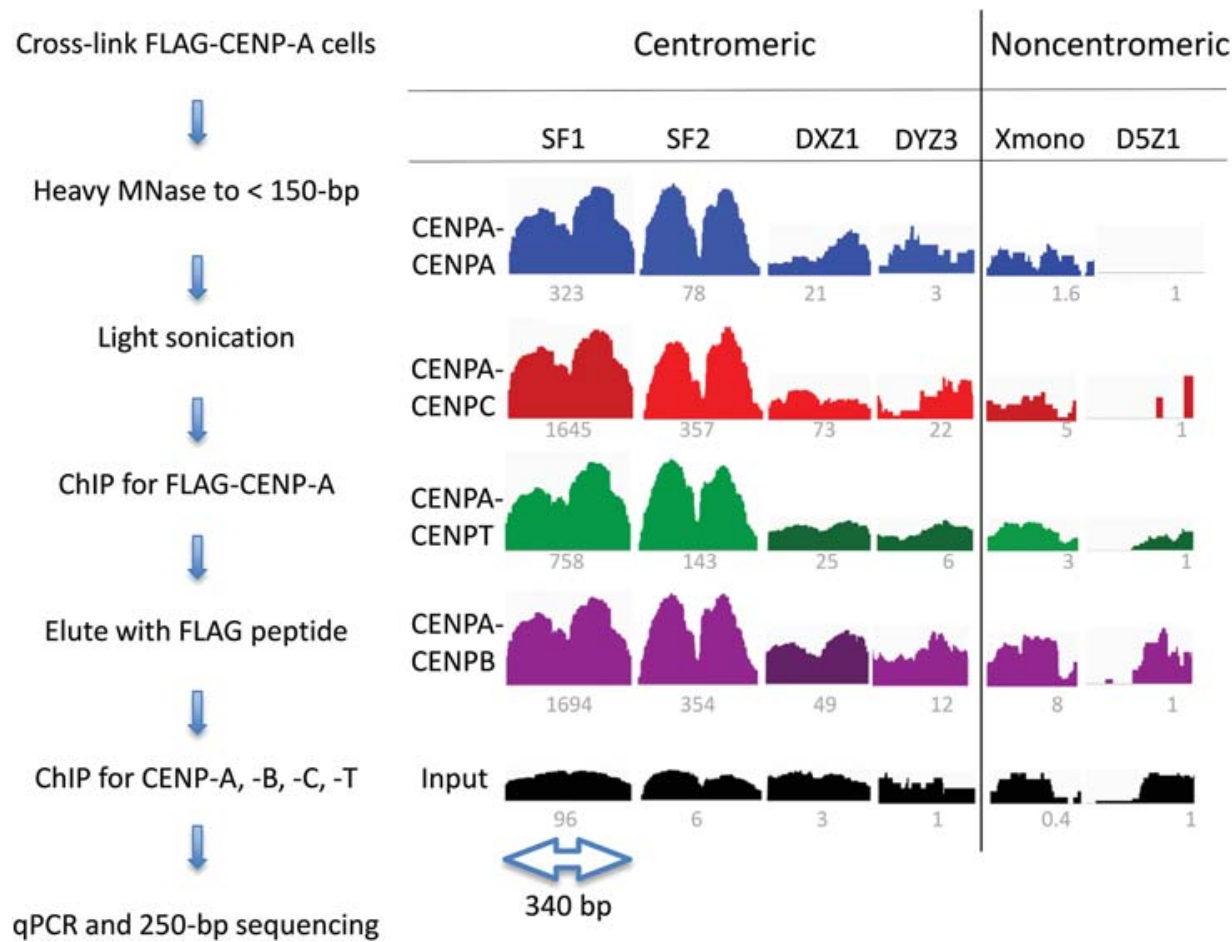

Figure 6. A coherent inner kinetochore complex occupies young human centromeric repeats. Sequential ChIP-seq profiles of CCAN components are nearly identical. A single $\alpha$-satellite dimer from each array is shown, and the relative scale is the area of the indicated profile divided by the area of the D5Z1 profile, in which the numbers reflect the product of the total sequence abundance and enrichment. Because DXZ1, DYZ3, D19Z1, Xmono, and D5Z1 are not dimeric units, we chose pairs of tandem monomers as representatives. (Based on data from Thakur and Henikoff 2016.)

\section{UNDERSTANDING THE EVOLUTIONARY PLASTICITY OF CENTROMERIC CHROMATIN}

These studies of centromeric chromatin in a wide variety of organisms have uncovered an astonishing diversity that is difficult to reconcile with the conserved function of centromeric chromatin, which is to anchor the outer kinetochore complex (Steiner and Henikoff 2015). What accounts for such remarkable centromeric chromatin plasticity?

Evolutionary plasticity of centromeric chromatin might arise from selfish processes. Centromere drive is a cyclical process, in which satellite sequences expand and compete for the egg pole at meiosis I but are suppressed by mutations in host CCAN and other proteins (Malik and Henikoff 2001). Successful drive of a satellite centromere may eventually result in fixation of that satellite sequence in the species evolving into a genetically defined centromere, whereas successful suppression of drive over evolutionary time tends to reduce centromere sequence specificity evolving into an epigenetically defined centromere (Dawe and Henikoff 2006). Interestingly, the cenH3s of the holocentric plant genus Luzula show no evidence of centromere drive, in contrast to the cenH3s of monocentric plants (Zedek and Bureš 2016), which suggests that elimination of a fixed position on the chromosome that can be colonized by selfish DNA may be an effective defense against centromere drive (Fig. 7; Talbert et al. 2008). In contrast, the holocentromeres in nematode oocyte meiosis are axially oriented so that the chromosome end functionally resembles a monocentromere (Albertson and Thomson 1993). This telokinetic form of chromosome disjunction may be less effective at avoiding centromere drive than the holokinetic disjunction of equatorially orientated Luzula chromosomes (Heckmann et al. 2014). Although the role of cenH3 in the cup-like kinetochore of Caenorhabditis meiosis is disputed (Chan et al. 2004; Monen et al. 2005), it differs between oocyte and spermatocyte meiosis (Shakes et al. 2009), and cenH3 shows evidence of positive selection (Zedek and Bureš 2012), suggesting that centromere drive may affect telokinetic holocentromeres. This may explain the massive accumulation of heterochromatic sequences at the ends of the single chromosome in Parascaris univalens (Talbert et al. 2008).

Whereas native human centromeres are genetically defined in that they are dominated by specific $\alpha$-satellite arrays on each centromere, rare cases of epigenetically defined human neocentromeres suggests that centromeric chromatin plasticity is an inevitable consequence of an ever-changing DNA sequence substrate for CCAN assembly. Other selfish processes may be responsible for transitions between different fungal centromere types, such as the proposed colonization of Saccharomycetes centromeres by its 2- $\mu \mathrm{m}$ plasmid (Malik and Henikoff 2009). 
meiotic parity, random segregation in females and males
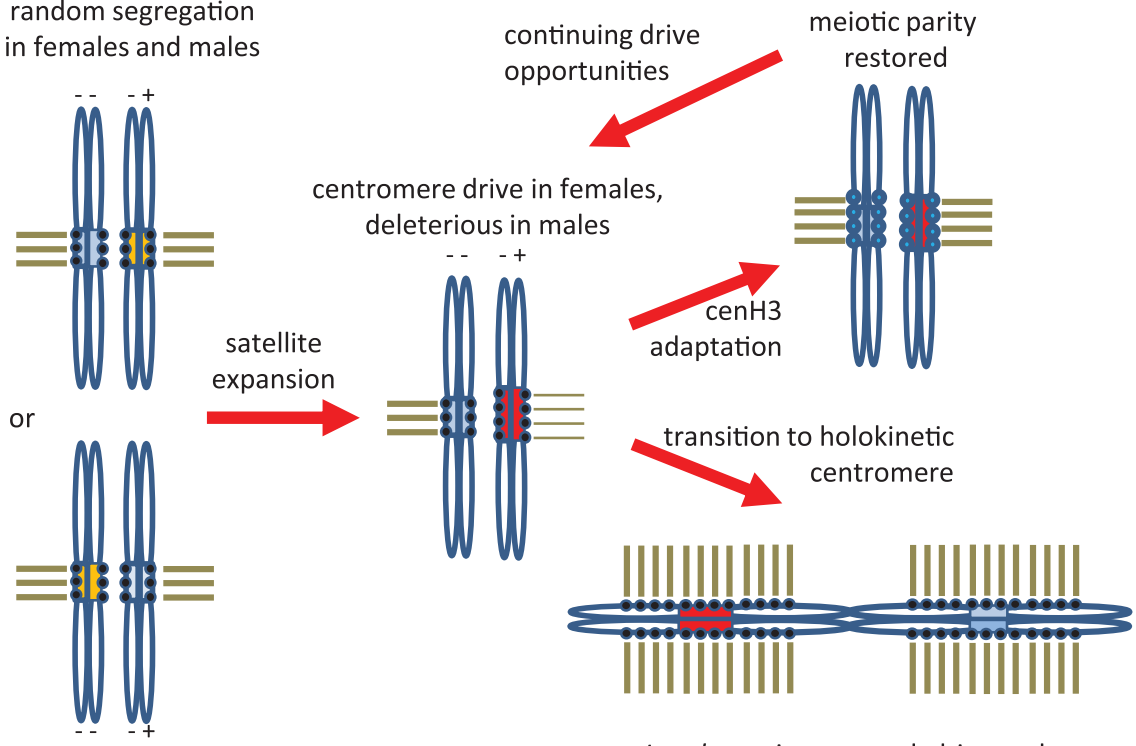

Luzula, parity restored, drive ends

Figure 7. Holokinetic meiosis suppresses centromere drive. In female meiosis, three meiotic products $(-)$ degenerate and one $(+)$ survives. With random segregation each chromatid in the meiotic tetrad has an equal opportunity to be oriented toward the egg pole. However, selfish DNA that influences centromere "strength" through greater assembly of kinetochore components may be preferentially transmitted (centromere drive), while simultaneously creating deleterious centromere imbalance in males. Adaptation of kinetochore proteins to restore centromere parity may suppress drive, but cycles of drive and suppression will repeat. In the holokinetic chromosomes of Luzula, the equatorial orientation of many broadly distributed kinetochore sites makes it difficult for any localized selfish element to gain a transmission advantage, effectively ending cycles of drive and suppression (Zedek and Bureš 2016).

One common feature of genetically defined centromeres, whether the point centromeres of Saccharomycetes or the satellite centromeres of animals and plants, is that they are well-positioned. In contrast, the central core of fission yeast regional centromeres lacks obvious sequence specificity and shows random positioning of nucleosomes (Thakur et al. 2015). Precise positioning of nucleosomes, which is especially evident in the satellite centromeres of rice (Zhang et al. 2013), is a sequence-specific adaptation of satellite DNA that has been exploited for the first successful crystallization of $\mathrm{H} 3$ nucleosomes, which were produced using a human $\alpha$-satellite DNA derivative (Harp et al. 1996; Luger et al. 1997). Precise phasing, together with the action of satellite-specific DNA-binding proteins, such as CENP-B, may represent the means whereby selfish centromeres perpetuate themselves. CENP-B is derived from the transposase encoded by the pogo DNA transposon, and it is attractive to imagine that its original domestication as a centromere protein was via recruitment by a driving centromere.

The domestication of selfish elements appears to be responsible for the most remarkable example of centromere evolution, the partial or complete replacement of the satellite centromeres of the wild ancestor of maize by a selfish element in maize inbred lines (Schneider et al. 2016). During domestication of maize from teosinte over the past $\sim 9000$ years, selection for agronomic traits was accompanied by dense insertion of CR2 centromerespecific retrotransposons and frequent loss by small inversions and deletions of the ancestral 155-bp CentC sat- ellite in all 10 maize centromeres, 57 times independently in 26 inbred lines. Domestication and inbreeding would thus appear to be a powerful driver of centromere plasticity and could account for the near-complete loss of satellite arrays at several rice (Nagaki et al. 2004) and potato (Gong et al. 2012) centromeres and the complete loss of repetitive sequences from horse Centromere 11 (Purgato et al. 2015). Thus, whether the direct result of centromere competition, the colonization by selfish elements, or the indirect result of domestication, strong selective forces appear to be drivers of the remarkable plasticity of centromeric chromatin.

\section{CONCLUSION}

Our investigations into the molecular basis for centromere function have uncovered an unexpected plasticity in chromatin architecture, with evidence for histone-containing particles that are unlike any nucleosomes observed on chromosome arms. These studies have led to evidence for centromeres with right-handed writhes, hemisomes, and coherent CCAN particles containing multiple centromere-specific histone-fold and nonhistone proteins. Such structural diversity might seem surprising considering the simplicity of the conserved function of centromeric chromatin to connect to the outer kinetochore. However, the centromere's control of its chromosome's fate at every cell division has unleashed powerful selfish and selective forces over evolutionary time and even during human domes- 
tication that have resulted in such interesting molecular complexity.

\section{ACKNOWLEDGMENTS}

We thank Mitchell Smith, who approximately 20 years ago pointed out that yeast Cse 4 and human CENP-A are no more similar to one another than to $\mathrm{H} 3$, a curious fact that led to our subsequent focus on histone variants and centromere evolution. We also thank former members of our laboratory whose work and insights over the years have contributed to this narrative.

\section{REFERENCES}

Akiyoshi B, Gull K. 2014. Discovery of unconventional kinetochores in kinetoplastids. Cell 156: 1247-1258.

Albertson DG, Thomson JN. 1993. Segregation of holocentric chromosomes at meiosis in the nematode, Caenorhabditis elegans. Chromosome Res 1: 15-26.

Alexandrov I, Kazakov A, Tumeneva I, Shepelev V, Yurov Y. 2001. $\alpha$-satellite DNA of primates: Old and new families. Chromosoma 110: 253-266.

Athwal RK, Walkiewicz MP, Baek S, Fu S, Bui M, Camps J, Ried T, Sung MH, Dalal Y. 2015. CENP-A nucleosomes localize to transcription factor hotspots and subtelomeric sites in human cancer cells. Epigenetics Chromatin 8: 2.

Bailey T, Elkan C. 1994. Fitting a mixture model by expectation maximization to discover motifs in biopolymers. In Proceedings of the Second International Conference on Intelligent Systems for Molecular Biology, pp. 28-36. AAAI Press, Menlo Park, CA.

Baum M, Sanyal K, Mishra PK, Thaler N, Carbon J. 2006. Formation of functional centromeric chromatin is specified epigenetically in Candida albicans. Proc Natl Acad Sci 103: 14877-14882.

Bradbury EM. 1977. Histone nomenclature. Methods Cell Biol 16: 179-181.

Brogaard K, Xi L, Wang JP, Widom J. 2012. A map of nucleosome positions in yeast at base-pair resolution. Nature 486: 496-501.

Buchwitz BJ, Ahmad K, Moore LL, Roth MB, Henikoff S. 1999. A histone-H3-like protein in C. elegans. Nature 401: 547-548.

Bui M, Dimitriadis EK, Hoischen C, An E, Quénet D, Giebe S, Nita-Lazar A, Diekmann S, Dalal Y. 2012. Cell-cycle-dependent structural transitions in the human CENP-A nucleosome in vivo. Cell 150: $317-326$.

Burt A, Trivers R. 2006. Genes in conflict: The biology of selfish genetic elements. Harvard University Press, Cambridge, MA.

Chan RC, Severson AF, Meyer BJ. 2004. Condensin restructures chromosomes in preparation for meiotic divisions. J Cell Biol 167: 613-625.

Chmátal L, Gabriel SI, Mitsainas GP, Martínez-Vargas J, Ventura J, Searle JB, Schultz RM, Lampson MA. 2014. Centromere strength provides the cell biological basis for meiotic drive and karyotype evolution in mice. Curr Biol 24: 2295-2300.

Clarke L, Carbon J. 1980. Isolation of a yeast centromere and construction of functional small circular chromosomes. Nature 287: 504-509.

Clarke L, Carbon J. 1985. The structure and function of yeast centromeres. Annu Rev Genet 19: 29-55.

Coffman VC, Wu P, Parthun MR, Wu JQ. 2011. CENP-A exceeds microtubule attachment sites in centromere clusters of both budding and fission yeast. J Cell Biol 195: 563-572.

Daniel A. 2002. Distortion of female meiotic segregation and reduced male fertility in human Robertsonian translocations: Consistent with the centromere model of co-evolving centromere DNA/centromeric histone (CENP-A). Am J Med Genet 111: $450-452$.
Dawe RK, Henikoff S. 2006. Centromeres put epigenetics in the driver's seat. Trends Biochem Sci 31: 662-669.

Díaz-Ingelmo O, Martínez-Garcia B, Segura J, Valdés A, Roca J. 2015. DNA topology and global architecture of point centromeres. Cell Rep 13: 667-677.

Drinnenberg IA, deYoung D, Henikoff S, Malik HS. 2014. Recurrent loss of $\mathrm{CenH} 3$ is associated with independent transitions to holocentricity in insects. Elife 3: e03676.

Drinnenberg IA, Henikoff S, Malik HS. 2016. Evolutionary turnover of kinetochore proteins: A ship of Theseus? Trends Cell Biol 26: 498-510.

Earnshaw WC, Rothfield N. 1985. Identification of a family of human centromere proteins using autoimmune sera from patients with scleroderma. Chromosoma 91: 313-321.

Fishman L, Willis JH. 2005. A novel meiotic drive locus almost completely distorts segregation in Mimulus (monkeyflower) hybrids. Genetics 169: 347-353.

Flemming W. 1882. Zellsubstanz, Kern und Zelltheilung. F.C.W. Vogel, Leipzig.

Furuyama S, Biggins S. 2007. Centromere identity is specified by a single centromeric nucleosome in budding yeast. Proc Natl Acad Sci 104: 14706-14711.

Furuyama T, Henikoff S. 2009. Centromeric nucleosomes induce positive DNA supercoils. Cell 138: 104-113.

Furuyama T, Codomo CA, Henikoff S. 2013. Reconstitution of hemisomes on budding yeast centromeric DNA. Nucleic Acids Res 41: 5769-5783.

Gassmann R, Rechtsteiner A, Yuen KW, Muroyama A, Egelhofer T, Gaydos L, Barron F, Maddox P, Essex A, Monen J, et al. 2012. An inverse relationship to germline transcription defines centromeric chromatin in C. elegans. Nature 484: 534-537.

Gerstein MB, Lu ZJ, Van Nostrand EL, Cheng C, Arshinoff BI, Liu T, Yip KY, Robilotto R, Rechtsteiner A, Ikegami K, et al. 2010. Integrative analysis of the Caenorhabditis elegans genome by the modENCODE project. Science 330: 17751787.

Gong Z, Wu Y, Koblízková A, Torres GA, Wang K, Iovene M, Neumann P, Zhang W, Novák P, Buell CR, et al. 2012. Repeatless and repeat-based centromeres in potato: Implications for centromere evolution. Plant Cell 24: 3559-3574.

Gore J, Bryant Z, Nöllmann M, Le MU, Cozzarelli NR, Bustamante C. 2006. DNA overwinds when stretched. Nature 442: 836-839.

Harp JM, Uberbacher EC, Roberson AE, Palmer EL, Gewiess A, Bunick GJ. 1996. X-ray diffraction analysis of crystals containing twofold symmetric nucleosome core particles. Acta Crystallogr D Biol Crystallogr 52: 283-288.

Harrington JJ, Van Bokkelen G, Mays RW, Gustashaw K, Willard HF. 1997. Formation of de novo centromeres and construction of first-generation human artificial microchromosomes. Nat Genet 15: 345-355.

Hasson D, Panchenko T, Salimian KJ, Salman MU, Sekulic N, Alonso A, Warburton PE, Black BE. 2013. The octamer is the major form of CENP-A nucleosomes at human centromeres. Nat Struct Mol Biol 20: 687-695.

Hayden KE, Strome ED, Merrett SL, Lee HR, Rudd MK, Willard HF. 2013. Sequences associated with centromere competency in the human genome. Mol Cell Biol 33: 763-772.

Heckmann S, Schubert V, Houben A. 2014. Holocentric plant meiosis: First sisters, then homologues. Cell Cycle 13: 36233624 .

Henikoff S, Henikoff JG. 2012. "Point" centromeres of Saccharomyces harbor single centromere-specific nucleosomes. Genetics 190: 1575-1577.

Henikoff S, Malik HS. 2002. Centromeres: Selfish drivers. $\mathrm{Na}$ ture 417: 227.

Henikoff S, Ahmad K, Platero JS, van Steensel B. 2000. Heterochromatic deposition of centromeric histone H3-like proteins. Proc Natl Acad Sci 97: 716-721.

Henikoff S, Ahmad K, Malik HS. 2001. The centromere paradox: Stable inheritance with rapidly evolving DNA. Science 293: 1098-1102. 
Henikoff S, Henikoff JG, Sakai A, Loeb GB, Ahmad K. 2009. Genome-wide profiling of salt fractions maps physical properties of chromatin. Genome Res 19: 460-469.

Henikoff JG, Belsky JA, Krassovsky K, Macalpine DM, Henikoff S. 2011. Epigenome characterization at single base-pair resolution. Proc Natl Acad Sci 108: 18318-18323.

Henikoff S, Ramachandran S, Krassovsky K, Bryson TD, Codomo CA, Brogaard K, Widom J, Wang JP, Henikoff JG. 2014. The budding yeast Centromere DNA Element II wraps a stable Cse4 hemisome in either orientation in vivo. Elife 3: $\mathrm{e} 01861$.

Henikoff JG, Thakur J, Kasinathan S, Henikoff S. 2015. A unique chromatin complex occupies young $\alpha$-satellite arrays of human centromeres. Sci Adv 1: e14000234.

Jin W, Melo JR, Nagaki K, Talbert PB, Henikoff S, Dawe RK, Jiang J. 2004. Maize centromeres: Organization and functional adaptation in the genetic background of oat. Plant Cell 16: 571-581.

Kang Y, Wang J, Neff A, Kratzer S, Kimura H, Davis RE. 2016. Differential chromosomal localization of centromeric histone CENP-A contributes to nematode programmed DNA elimination. Cell Rep 16: 2308-2316.

Ketel C, Wang HS, McClellan M, Bouchonville K, Selmecki A, Lahav T, Gerami-Nejad M, Berman J. 2009. Neocentromeres form efficiently at multiple possible loci in Candida albicans. PLoS Genet 5: e1000400.

Krassovsky K, Henikoff JG, Henikoff S. 2012. Tripartite organization of centromeric chromatin in budding yeast. Proc Natl Acad Sci 109: 243-248.

Lacoste N, Woolfe A, Tachiwana H, Garea AV, Barth T, Cantaloube S, Kurumizaka H, Imhof A, Almouzni G. 2014. Mislocalization of the centromeric histone variant CenH3/CENP$\mathrm{A}$ in human cells depends on the chaperone DAXX. Mol Cell 53: 631-644.

Lawrimore J, Bloom KS, Salmon ED. 2011. Point centromeres contain more than a single centromere-specific Cse4 (CENPA) nucleosome. J Cell Biol 195: 573-582.

Luger K, Mader AW, Richmond RK, Sargent DF, Richmond TJ. 1997. Crystal structure of the nucleosome core particle at $2.8 \mathrm{~A}$ resolution. Nature 389: 251-260.

Malik HS, Henikoff S. 2001. Adaptive evolution of Cid, a centromere-specific histone in Drosophila. Genetics 157: 1293-1298.

Malik HS, Henikoff S. 2009. Major evolutionary transitions in centromere complexity. Cell 138: 1067-1082.

McKinley KL, Cheeseman IM. 2016. The molecular basis for centromere identity and function. Nat Rev Mol Cell Biol 17: 16-29.

Melters DP, Paliulis LV, Korf IF, Chan SW. 2012. Holocentric chromosomes: Convergent evolution, meiotic adaptations, and genomic analysis. Chromosome Res 20: 579-593.

Meluh PB, Yang P, Glowczewski L, Koshland D, Smith MM. 1998. Cse $4 p$ is a component of the core centromere of Saccharomyces cerevisiae. Cell 94: 607-613.

Mizuguchi G, Xiao H, Wisniewski J, Smith MM, Wu C. 2007. Nonhistone Scm 3 and histones CenH3-H4 assemble the core of centromere-specific nucleosomes. Cell 129: $1153-1164$.

Monen J, Maddox PS, Hyndman F, Oegema K, Desai A. 2005. Differential role of CENP-A in the segregation of holocentric C. elegans chromosomes during meiosis and mitosis. Nat Cell Biol 7: 1148-1155.

Nagaki K, Cheng Z, Ouyang S, Talbert PB, Kim M, Jones KM, Henikoff S, Buell CR, Jiang J. 2004. Sequencing of a rice centromere uncovers active genes. Nat Genet 36: 138145

Nechemia-Arbely Y, Fachinetti D, Miga KH, Sekulic N, Soni GV, Kim DH, Wong AK, Lee AY, Nguyen K, Dekker C, et al. 2017. Human centromeric CENP-A chromatin is a homotypic, octameric nucleosome at all cell cycle points. J Cell Biol 216: 607-621.

Novitski E. 1955. Genetic measures of centromere activity in Drosophila melanogaster. J Cell Comp Physiol 45: 151169.
Padmanabhan S, Thakur J, Siddharthan R, Sanyal K. 2008. Rapid evolution of Cse4p-rich centromeric DNA sequences in closely related pathogenic yeasts, Candida albicans and Candida dubliniensis. Proc Natl Acad Sci 105: $19797-$ 19802.

Palmer DK, Margolis RL. 1985. Kinetochore components recognized by human autoantibodies are present on mononucleosomes. Mol Cell Biol 5: 173-186.

Palmer DK, O’Day K, Wener MH, Andrews BS, Margolis RL. 1987. A $17-\mathrm{kD}$ centromere protein (CENP-A) copurifies with nucleosome core particles and with histones. J Cell Biol 104: 805-815.

Palmer DK, O’Day K, Margolis RL. 1990. The centromere specific histone CENP-A is selectively retained in discrete foci in mammalian sperm nuclei. Chromosoma 100: 32-36.

Purgato S, Belloni E, Piras FM, Zoli M, Badiale C, Cerutti F, Mazzagatti A, Perini G, Della Valle G, Nergadze SG, et al. 2015. Centromere sliding on a mammalian chromosome. Chromosoma 124: 277-287.

Rhoades MM. 1952. Preferential segregation in maize. In Heterosis (ed. Gowen JW), pp. 66-80. Iowa State College Press, Ames.

Sanders MM. 1978. Fractionation of nucleosomes by salt elution from micrococcal nuclease-digested nuclei. J Cell Biol 79: 97 109.

Schneider KL, Xie Z, Wolfgruber TK, Presting GG. 2016. Inbreeding drives maize centromere evolution. Proc Natl Acad Sci 113: E987-E996.

Schrader F. 1935. Notes on the mitotic behavior of long chromosomes. Cytologia (Tokyo) 6: 422-430.

Senaratne AP, Drinnenberg IA. 2017. All that is old does not wither: Conservation of outer kinetochore proteins across all eukaryotes? J Cell Biol 216: 291-293.

Shakes DC, Wu JC, Sadler PL, Laprade K, Moore LL, Noritake A, Chu DS. 2009. Spermatogenesis-specific features of the meiotic program in Caenorhabditis elegans. PLoS Genet 5: e1000611.

Skene PJ, Henikoff S. 2017. An efficient targeted nuclease strategy for high-resolution mapping of DNA binding sites. Elife 6: e21856.

Steiner FA, Henikoff S. 2014. Holocentromeres are dispersed point centromeres localized at transcription factor hotspots. Elife 3: e02025.

Steiner FA, Henikoff S. 2015. Diversity in the organization of centromeric chromatin. Curr Opin Genet Dev 31: 28-35.

Struhl K, Segal E. 2013. Determinants of nucleosome positioning. Nat Struct Mol Biol 20: 267-273.

Sturtevant AH. 1913. The linear arrangement of six sex-linked factors in Drosophila, as shown by their mode of association. $J$ Exp Zool 14: 43-59.

Talbert PB, Masuelli R, Tyagi AP, Comai L, Henikoff S. 2002. Centromeric localization and adaptive evolution of an Arabidopsis histone H3 variant. Plant Cell 14: 1053-1066.

Talbert PB, Bryson TD, Henikoff S. 2004. Adaptive evolution of centromere proteins in plants and animals. J Biol 3: 18 .

Talbert PB, Bayes JJ, Henikoff S. 2008. Evolution of centromeres and kinetochores: A two-part fugue. In The kinetochore (ed. De Wulf P, Earnshaw WC). Springer, Berlin.

Talbert PB, Ahmad K, Almouzni G, Ausio J, Berger F, Bhalla PL, Bonner WM, Cande WZ, Chadwick BP, Chan SW, et al. 2012. A unified phylogeny-based nomenclature for histone variants. Epigenetics Chromatin 5: 7.

Tatchell K, Van Holde KE. 1979. Nucleosome reconstitution: Effect of DNA length on nuclesome structure. Biochemistry (Mosc) 18: 2871-2880.

Thakur J, Henikoff S. 2016. CENPT bridges adjacent CENPA nucleosomes on young human $\alpha$-satellite dimers. Genome Res 26: $1178-1187$.

Thakur J, Sanyal K. 2013. Efficient neocentromere formation is suppressed by gene conversion to maintain centromere function at native physical chromosomal loci in Candida albicans. Genome Res 23: 638-652. 
Thakur J, Talbert PB, Henikoff S. 2015. Interactions of inner kinetochore proteins with fission yeast regional centromeres. Genetics 201: 543-561.

Wisniewski J, Hajj B, Chen J, Mizuguchi G, Xiao H, Wei D, Dahan M, Wu C. 2014. Imaging the fate of histone Cse4 reveals de novo replacement in S phase and subsequent stable residence at centromeres. Elife 3: e02203.

Yunis JJ, Yasmineh WG. 1971. Heterochromatin, satellite DNA, and cell function. Structural DNA of eucaryotes may support and protect genes and aid in speciation. Science 174: 12001209.
Zedek F, Bureš P. 2012. Evidence for centromere drive in the holocentric chromosomes of Caenorhabditis. PLoS One 7: e30496.

Zedek F, Bureš P. 2016. Absence of positive selection on CenH3 in Luzula suggests that holokinetic chromosomes may suppress centromere drive. Ann Bot 118: 1347-1352.

Zhang T, Talbert PB, Zhang W, Wu Y, Yang Z, Henikoff JG, Henikoff S, Jiang J. 2013. The CentO satellite confers translational and rotational phasing on cenH3 nucleosomes in rice centromeres. Proc Natl Acad Sci 110: E4875E4883. 


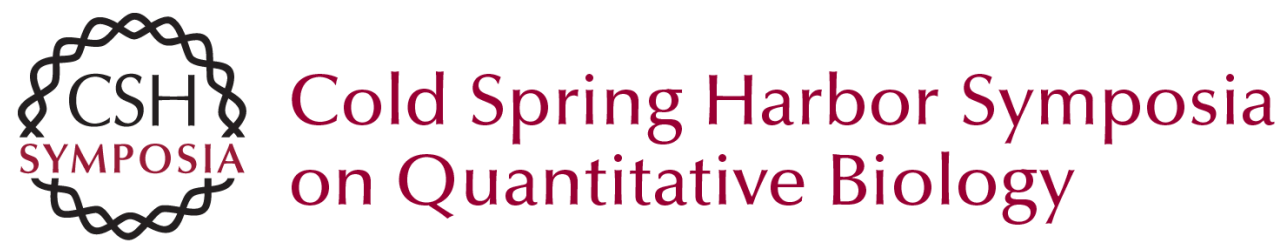

\section{Remarkable Evolutionary Plasticity of Centromeric Chromatin}

Steven Henikoff, Jitendra Thakur, Sivakanthan Kasinathan, et al.

Cold Spring Harb Symp Quant Biol 2017 82: 71-82 originally published online December 1, 2017 Access the most recent version at doi:10.1101/sqb.2017.82.033605

References This article cites 85 articles, 30 of which can be accessed free at: http://symposium.cshlp.org/content/82/71.full.html\#ref-list-1

Creative This article is distributed under the terms of the

Commons http://creativecommons.org/licenses/by/4.0/, which permits unrestricted

License reuse and redistribution provided that the original author and source are credited.

Email Alerting Receive free email alerts when new articles cite this article - sign up in Service the box at the top right corner of the article or click here. 